SPECIAL COMMUNICATION

\title{
The case of the disappearing nitrosamines: a potentially global phenomenon
}

N Gray, P Boyle

Tobacco Control 2004;13:13-16. doi: 10.1136/tc.2003.005579

The cigarette usually carries in its smoke significant doses of carcinogenic tobacco specific nitrosamines (TSNAs), which have been implicated as causes of oral, lung, oesophageal, and pancreatic cancer. However, there is substantial variation in nitrosamine content of the smoke of modern cigarettes. This variation is both unacceptable and unnecessary, as TSNAs can be readily removed during the manufacturing process. Removing a known carcinogen needs no justification, even though proof of benefit may not be forthcoming for decades.

See end of article for authors' affiliations

Correspondence to: N Gray, Division of Epidemiology and Biostatistics, European Institute of Oncology, via Ripamonti 435, 20141 Milan, Italy; nigel@uicc.ch

Received 1 August 2003 Accepted 8 January 2004
$\mathrm{T}$ he world has approximately one billion tobacco smokers ${ }^{1}$ and an unknown, but large, number of users of other forms (mostly chewed) of tobacco. A high proportion of these tobacco users are addicted to nicotine. The cigarette is the most efficient form of nicotine delivery system yet devised ${ }^{2}$ and usually, but not inevitably, carries in its smoke significant doses of carcinogenic tobacco specific nitrosamines (TSNAs), as well as a galaxy of other proven carcinogens and toxins (toxicants).

When harvested the tobacco plant contains nitrates but not nitrosamines. TSNAs are formed during the process of curing and combustion but are dependent on levels of nitrate ${ }^{3-5}$ and a number of other factors such as filter ventilation and total volume inhaled. ${ }^{6}$ The way in which the product is cured, by air or by heat using various sources including propane gas, is crucial. ${ }^{5}$ Since use of nitrate fertilisers, curing methods and filter ventilation are all under the control of the manufacturer, so is the level of nitrosamine presented to the smoker.

TSNAs have been implicated as causes of oral cancer, lung cancer, oesophageal cancer and pancreatic cancer. ${ }^{7}$ Of particular interest in human lung cancer is 4-(methylnitrosamino)-1(3-pyridyl)-1-butanone (NNK). ${ }^{8}$ NNK induces tumours of these four tissues in several animal models independent of the route of administration. The TSNAs are regarded as important contributors to adenocarcinoma. ${ }^{9}$ NNK induced adducts of DNA are seen in human lung cancers. ${ }^{10}$ The relative increase of NNK is thought to contribute to the relative increase in adenocarcinoma seen over time in many countries.

\section{THE CASE FOR REDUCING NITROSAMINES}

The case for reducing the amount of nitrosamine in mainstream smoke has a threefold base. The first is that nitrosamine formation can be reduced virtually to zero during manufacture and processing. ${ }^{11}$ The second is that there is simply no logical reason why a removable carcinogen should be allowed to remain in a consumer product-it is inconceivable that a toothpaste manufacturer would be allowed to add a carcinogen for flavour or aroma purposes. The third is that there are cigarettes on the market (for example, in Australia) with nondetectable levels of the nitrosamine NNK when tested under the International Standard Organisation (ISO) measurement system (it is reasonable to use NNK as a surrogate for other TSNAs). This last point establishes feasibility. Removing a known carcinogen needs no further justification even though proof of benefit may not be forthcoming for decades.

The authors and others ${ }^{4}{ }^{12-18}$ have repeatedly drawn attention to the substantial variation in nitrosamine content of the smoke of modern cigarettes. This variation is both unacceptable and unnecessary.

At long last it seems that the tobacco industry in the USA has got the message. As early as December 1999 RJ Reynolds announced that it would be progressively moving towards low nitrosamine tobaccos and would be providing funds for retrofitting tobacco curing barns. ${ }^{19}$ Philip Morris has done the same ${ }^{20}$ working with the Tobacco Industry Leadership Group, and has also provided funds to assist with the changeover. By December 2001 the US Department of Agriculture's Commodity Credit Corporation was indicating that price support would become unavailable for tobacco cured in barns that have not been retrofitted with heat exchangers that provide an indirect heat source. ${ }^{21}$ This is a return to a system similar to that used until the 1970s in the USA ${ }^{20}$ which suggests that high nitrosamine tobacco is a relatively recent development, at least in the USA. Some tobacco from Brazil and Zimbabwe is low in nitrosamine. ${ }^{20}$ The Canadian tobacco industry is also requiring that they be supplied with low nitrosamine tobacco and this year's crop is almost all TSNA reduced..$^{22}$

There is little temporal information about levels of nitrosamines in tobacco smoke although Hoffmann $^{5}$ has followed a single US non-filter brand over several decades and shown a substantial increase in NNK in the smoke. Work in

\footnotetext{
Abbreviations: ISO, International Standard Organisation; NNK, 4-(methylnitrosamino)-1-(3-pyridyl)1-butanone; TSNAs, tobacco specific nitrosamines
} 


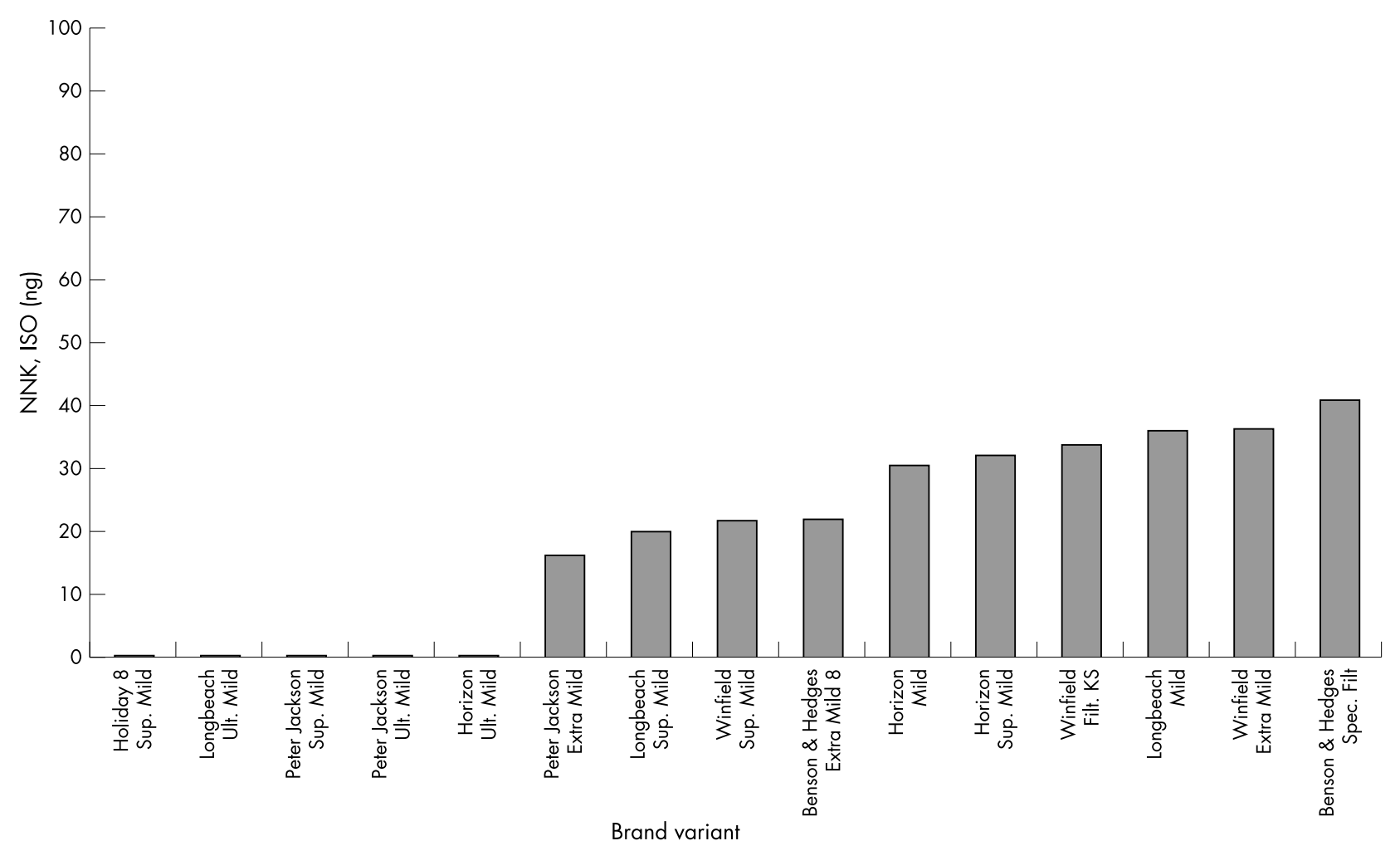

Figure 1 NNK levels (ng/cigarette), ISO measurement, in 15 popular Australian brands.

the late ' 80 s and early '90s revealed a wide variation in yields of NNK from undetectable levels up to 400-500 ng per cigarette $^{4}$ in the smoke of cigarettes from a variety of countries. Analysis of a single brand (Marlboro) purchased in 1996 in 30 countries $^{12}$ showed a ninefold variation in NNK between $36 \mathrm{ng}$ and $326 \mathrm{ng}$ per cigarette. These results were all obtained using the ISO measurement system (puff volume of $35 \mathrm{ml}$ every 60 seconds to a butt length of $23 \mathrm{~mm}$ ).

Recent brand specific data from Australia, tested by the ISO method in 2001, is shown in fig 1. This shows mainstream smoke levels of NNK for 15 popular Australian brands. ${ }^{23}$ Five brands show undetectable levels and the highest found in this sample was $41 \mathrm{ng}$ per cigarette.

Data from Canada ${ }^{24}$ for a sample of 27 brands tested by the ISO method had a range of NNK between 21-51 ng per cigarette. A summary of these data is presented in table 1, together with the levels of NNK found when the same sample was tested by the "intense" system devised by Health Canada (puff volume of $55 \mathrm{ml}$ at a frequency of 30 seconds with all ventilation holes blocked). ${ }^{25}$.

It is clear from the Australian data in table 1 that it would be feasible now to set an ISO tested limit for NNK of zero (effectively less than $4 \mathrm{ng}$ per cigarette) for cigarettes, or of $40 \mathrm{ng} /$ cigarette if the intense method of testing is used. One third of the sample meets this standard already, and what is possible for five brands is possible for all, if regulations prescribe it.

Consideration of this change in industry behaviour, and this limited data, gives rise to a number of public health questions.

\section{IS THE ISO TESTING SYSTEM A SUITABLE BASIS FOR COMPARISON?}

The answer to this is obviously no. There are two major issues relevant to the ISO testing system.

The first is that the test is seriously misleading to the consumer ${ }^{26-30}$ and serves the tobacco industry's interests in sustaining misleading descriptors such as "light" and "mild". It is a matter of urgency that the current misinformation be removed from the pack and that a more accurate and realistic alternative is found to indicate likely toxicant yields from cigarettes.

The second issue is that regulation of toxicants, and particularly nitrosamines, is also urgent. For regulatory

Table 1 Levels of NNK per cigarette, mainstream smoke, as determined by ISO testing and the intense testing system devised by Health Canada.

\begin{tabular}{lllll}
\hline Origin & Low ng & High ng & Year & Sample \\
\hline ISO testing & ND & 470 & 1990 & Global, multiple \\
Fischer & 54 & 326 & 1996 & Marlbro, 30 countries \\
Gray & ND & 41 & 2001 & 15 brands \\
Australia & 21 & 86 & 2002 & 27 brands \\
Canada & & & & \\
Intense testing system & 38 & 94 & 2001 & Same 15 brands \\
Australia & 58 & 138 & 2002 & Same 27 brands \\
Canada & & & \\
\hline ND, not done. & & & \\
\hline
\end{tabular}


purposes a comparative test is essential, and will necessarily be machine based (although validation tests in humans might be part of such a system). A two stage system has been proposed $^{29}$ and would be an improvement. However, the Canadian system has the merit of providing a high total smoke volume thereby revealing higher as well as more realistic levels of toxicants. It also blocks all filter ventilation, which is consistent with the abolition of filter ventilation which has been suggested ${ }^{27}$ as a means of minimising compensatory smoking.

\section{IS IT ACCEPTABLE THAT CARCINOGEN DOSE BE VARIED FOR FLAVOUR AND AROMA?}

It may appear strange to even pose this question, but it seems that nitrosamine rich tobaccos are valued for this reason. A representative of the China Tobacco Industry made this point in a discussion at the meeting of the Scientific Advisory Committee of the World Health Organization in February 2002. ${ }^{31}$ Of course the answer to the specific question has to be a resounding no. Carcinogen dose should be as low as practicable and in the case of nitrosamines this is either zero or something very close to it.

\section{CAN THIS TREND TOWARDS LOW NITROSAMINE CIGARETTES BE MADE GLOBAL?}

The answer to this is yes, with some difficulty. The international tobacco trade is complicated, often based on an auction system, and the introduction of nitrosamine assays on unmanufactured tobacco would be difficult. Certainly regulations could enforce a prohibition on manufacture and sale of high nitrosamine tobacco, but both import and export regulation would be required by many countries, and would need to be applied to tobacco as well as tobacco products. While all this is possible in theory, in practice it is likely that the developed countries will protect themselves best and others probably not at all. Voluntary agreements arouse profound scepticism among public health policymakers. However, it may be that, in this case, fear of US style litigation may be a more potent driving force for the international tobacco industry (which has undergone substantial rationalisation in recent years) to remove nitrosamines from its products. Major brands at least carry identification marks, and random sampling on a global basis as has been done on an exploratory basis ${ }^{12}$ would soon identify high nitrosamine products.

Such work is under way in the laboratories of the US Centers for Disease Control and Prevention in Atlanta ${ }^{32}$ and has already revealed the same wide diversity of nitrosamine content in the tobacco of global cigarette brands referred to above. It may be that more monitoring of global brands will have a substantial effect on the behaviour of tobacco manufacturers, as might random sampling of smokers' urine for NNK breakdown products.

\section{CONCLUSION}

Removing one (removable) class of carcinogens will not produce a non-carcinogenic cigarette and, although it may contribute to a reduction in adenocarcinoma of the lung and larynx, it will do nothing for other causes of premature mortality such as heart disease. Setting upper limits for other carcinogens and toxins ${ }^{13-172733} 34$ is possible and urgent. The rationale for this policy is that reduction in dose is (very) likely to reduce effects on active smokers (but not in passive smokers).

This review establishes that clearly the knowledge exists to reduce nitrosamines to minimal levels and that this is occurring in Australia and likely to occur in the USA and Canada. Public health policymakers need to pay attention to this and further legislation could make this compulsory as

\section{What this paper adds}

Tobacco and tobacco smoke contain multiple carcinogens. Among the most important are the tobacco specific nitrosamines (TSNAs) of which NNK (4-(methylnitrosamino)-1-(3-pyridyl)-1-butanone) is perhaps the most important. NNK preferentially produces adenocarcinoma in animals, and DNA adducts in the lungs of humans with lung cancer.

Nitrosamines are formed during the curing process and can be reduced to near zero levels in both tobacco and tobacco smoke. The US and Canadian manufacturers are moving towards low nitrosamine tobaccos, and some Australian brands are already showing smoke levels of zero when measured by the ISO system. Policymakers need to attempt to make this process global.

well as global. However, this is not the end of the story by any means. Industry may claim that its TSNA reduction policy is in the context of their "duty of care" to its customers, but why did they not take this step years ago (when the technology was available)? It also begs the question about what else the industry knows and can do about carcinogens and toxins in its product. Removing TSNAs should be just the beginning.

\section{ACKNOWLEDGEMENTS}

This work was conducted within the framework of support from the Associazione Italiana per la Ricerca sul Cancro (Italian Association for Cancer Research).

\section{Authors' affiliations}

N Gray, P Boyle, Division of Epidemiology and Biostatistics, European Institute of Oncology, Milan, Italy

\section{REFERENCES}

1 Peto R, Lopez AD, Boreham J, et al. Mortality from smoking in developed countries 1950-2000. Oxford: Oxford University Press, 1994.

2 National Cancer Institute. Risks associated with smoking cigarettes with low machine-measured yields of tar and nicotine. Bethesda, Maryland: US Department of Health and Human Services, National Institutes of Health, National Cancer Institute, 2001.

3 Fischer S, Spiegelhalder B, Eisenbarth J, et al. Investigations on the origin of tobacco-specific nitrosamines in mainstream smoke of cigarettes. Carcinogenesis 1990;11:723-30.

4 Fischer S, Spiegelhalder B, Preussmann R. Tobacco-specific nitrosamines in European and USA cigarettes. Arch Geschwulstforsch 1990;60:169-77.

5 Hoffmann D, Hoffmann I. The changing cigarette: chemical studies and bioassays. In: Risks Associated with smoking cigarettes with low machinemeasured yields of tar and nicotine. Bethesda, Maryland: US Department of Health and Human Services, National Institutes of Health, National Cancer Institute, 2001:159-91.

6 Fischer S, Spiegelhalder B, Preussmann R. Tobacco-specific nitrosamines in commercial cigarettes: possibilities for reducing exposure. IARC Sci Publ $1991 ; 105: 489-92$

7 Hecht SS, Hoffmann D. N-nitroso compounds and tobacco-induced cancers in man. IARC Sci Publ 1991:54-61.

8 Hecht SS. Tobacco smoke carcinogens and lung cancer. J Natl Cancer Inst 1999;91:1194-210.

9 Hoffmann D, Brunnemann KD, Prokopczyk B, et al. Tobacco-specific $\mathrm{N}$-nitrosamines and Areca-derived $\mathrm{N}$-nitrosamines: chemistry, biochemistry, carcinogenicity, and relevance to humans. J Toxicol Environ Health 1994;41:1-52.

10 Hecht SS. DNA adduct formation from tobacco-specific $\mathrm{N}$-nitrosamines. Mutat Res 1999:424:127-42.

11 Tobacco Agriculture and Star. Star Scientific. 2003. http:// www.starscientific.com/frame_pages/agriculture_frame.htm. (Accessed 2 February 2003).

12 Gray N, Zaridze D, Robertson C, et al. Variation within global cigarette brands in tar, nicotine, and certain nitrosamines: analytic study. Tobacco Control 2000;9:351.

13 Gray N, Boyle P. The regulation of tobacco and tobacco smoke. Ann Oncol 2000;11:909-14.

14 Gray N, Boyle P, Zatonski W. Tar concentrations in cigarettes and carcinogen content. Lancet 1998;352:787-8. 
15 Gray N, Zatonski W, Boyle P. Regulation of carcinogens in cigarettes. Lancet 1999;354:1036.

16 Gray N, Zaridze D, Robertson C, et al. Variation within global cigarette brands in tar, nicotine, and certain nitrosamines: analytic study. Tobacco Control 2000;9:351.

17 Gray N, Boyle P. The regulation of tobacco and tobacco smoke. Ann Oncol 2000;11:909-14.

18 Hoffmann D, Hoffmann I. The changing cigarette, 1950-1995. J Toxicol Environ Health 1997:50:307-64.

19 PR Newswire. Reynolds Tobacco will use flue-cured toabcco low in nitrosamines. Action on Smoking and Health. 2 December 1999. http:// www.no-smoking.org/dec99/12-03-99-3.html. (Accessed 7 March 2003)

20 Caldwell D. Back to the future. North Carolina tobacco growers deal with their latest challenge. The Dean, College of Agriculture and Life Sciences. Perspectives on Line, The magazine of the College of Agriculture and Life Sciences, 2001. University of North Carolina. http://www.cals.ncsu.edu/ agcomm/magazine/winter01/back.htm. (Accessed 7 March 2003).

21 Moore JM. CCC announces changes in flue-cured tobacco curing-barn certification program. Moore JM. University of Georgia Extension Agronomist-Tobacco . 12-21-2000. University of Georgia. http:// www.no-smoking.org/dec99/12-03-99-3.html. (Accessed 7 March 2003).

22 Bexon R. Canadian purchase of low nitrosamine tobacco. Bexon, R. 17 September 2001. http://www.smoke-free.ca/eng_home/ news_press_Mar6_2001.htm. (Accessed 2 February 2003).

23 Australian Department of Health and Ageing. http://www.health.gov.au/ pubhlth/strateg/drugs/tobacco/emis_data.htm. (Accessed 2 February 2003)
24 Kaiserman M. TSNA levels in Canadian Cigarettes. 10 July, 2003.

25 Health Canada. Canadian Tobacco Reporting Regulations. Health Canada. http://www.hc-sc.gc.ca/hecs-sesc/tobacco/legislation/ prop may 36c.html. (Accessed 22 July 2003).

26 Diordjevic MV, Stellman SD, Zang E. Doses of nicotine and lung carcinogens delivered to cigarette smokers. J Natl Cancer Inst 2000;92:106-1 1.

27 Gray N, Kozlowski LT. More on the regulation of tobacco smoke: how we got here and where next. Ann Oncol 2003;14:353-7.

28 Kozlowski LT, O'Connor RJ. Cigarette filter ventilation is a defective design because of misleading taste, bigger puffs, and blocked vents. Tobacco Control 2002;11(suppl I):i40-50.

29 Kozlowski LT, O'Connor RJ. Official cigarette tar tests are misleading: use a two-stage, compensating test. Lancet 2000;355:2159-61.

30 Kozlowski LT, Rickert WS, Pope MA, et al. Estimating the yield to smokers of tar, nicotine, and carbon monoxide from the 'lowest yield' ventilated filtercigarettes. Br J Addict 1982;77:159-65.

31 Gray N, Connolly G. Nitrosamine rich tobaccos are valued for flavour and aroma-Chinese tobacco company representative 2002;2

32 Ashley DL, Beeson MD, Johnson DR et al. Tobacco-specific nitrosamines in tobacco from U.S. brand and non-U.S. brand cigarettes. Nicotine Tob Res 2003;5:323-31.

33 Gray N. Reflections on the saga of tar content: why did we measure the wrong thing? Tobacco Control 2000;9:90-4.

34 Gray N, Boyle P. Regulation of cigarette emissions. Ann Oncol 2002;13:19-21.

\section{The lighter side}

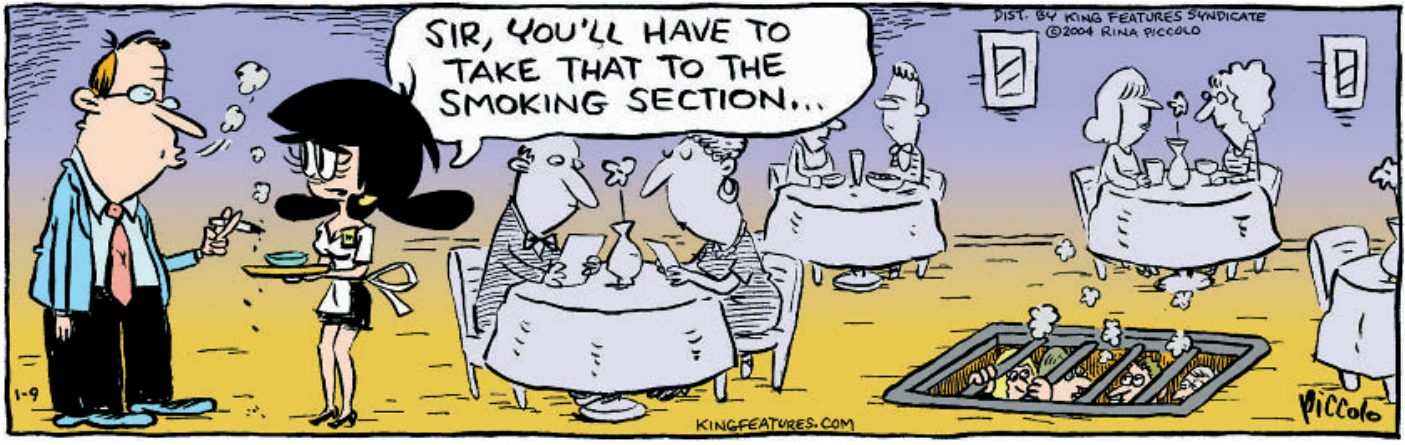

(c) King Features Syndicate. Reprinted with permission of Torstar Syndication Services. 